\title{
Caracterização fisiologica de mudas de Jatropha curcas $L$. produzidas em diferentes níveis de irradiância
}

\section{Physiological characterization of Jatropha curcas L. plants grown under different levels of irradiance}

FÁBIO SANTOS MATOS ${ }^{1,3}$

CLEILTON VASCONCELOS MOREIRA²

ROBSON FERNANDO MISSIO'

LUÍZ ANTÔNIO DOS SANTOS DIAS'

Dos frutos de Jatropha curcas L. Foto: R.F. Missio

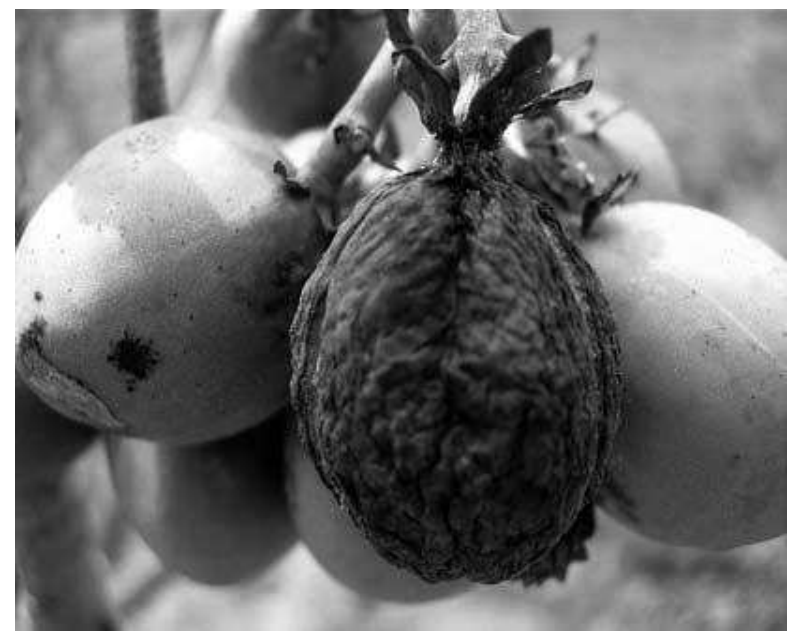

\section{RESUMO}

O incremento dos níveis dos gases de efeito estufa, notadamente dióxido de carbono $\left(\mathrm{CO}_{2}\right)$ na atmosfera terrestre, tem intensificado a busca por combustíveis renováveis, tipo biodiesel, visando reduzir o consumo de combustíveis fósseis, responsáveis por $40 \%$ das emissões de $\mathrm{CO}_{2}$. Diversas são as vantagens do uso do biodiesel em comparação ao diesel de petróleo, dentre elas destaca-se a sustentabilidade do ecossistema. Neste contexto, a espécie Jatropha curcas é uma importante alternativa para produção de biodiesel. Neste trabalho, avaliou-se o efeito da irradiância sobre as características fisiológicas de folhas de J. curcas. O experimento foi conduzido em Viçosa ( $20^{\circ} 45^{\prime} \mathrm{S}, 42^{\circ} 54^{\prime} \mathrm{W}$; $650 \mathrm{~m}$ de altitude), Minas Gerais, Brasil. Sementes de J. curcas foram semeadas em vasos plásticos de $12 \mathrm{~L}$, contendo uma mistura de $30 \%$ de areia e $70 \%$ de solo. Metade das mudas foram cultivadas sob telado com $40 \%$ da radiação solar, e a outra metade a pleno sol. A irradiância de saturação foi semelhante entre os dois sistemas de cultivo. Entretanto, as plantas cultivadas a pleno sol apresentaram maiores fotossíntese, irradiância de compensação e acúmulo de massa seca. Estes resultados sugerem uma relativa aclimatação da maquinaria fotossintética de J. curcas à variação da irradiância.

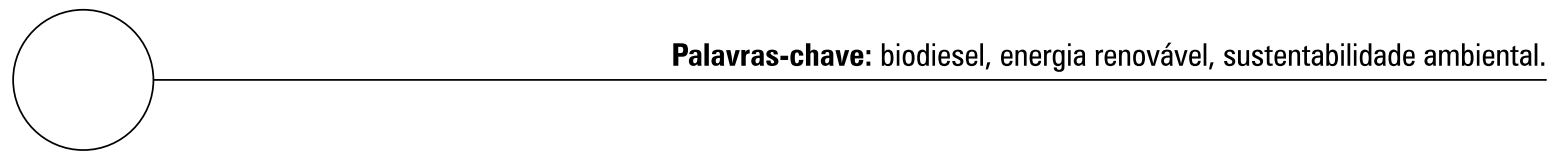

\footnotetext{
Departamento de Fitotecnia (DFT), Universidade Federal de Viçosa (UFV), Viçosa, MG, Brasil.

Universidade Federal de Lavras (UFLA), Lavras, MG, Brasil.

Autor para correspondência. fabio.agronomia@hotmail.com
} 


\section{ABSTRACT}

The increase in carbon dioxide levels in the atmospheres has intensified the search for renewable fuel sources in order to further reduce the consumption of fossil fuel. There are several advantages of employing biodiesel as compared to conventional diesel, but the main benefit of using biodiesel is the sustainability of the ecosystem. In this context, the species Jatropha curcas is an important alternative for production of biodiesel. This study aimed at assessing the effects of irradiation on the physiological characteristics of leaves of that species. The experiment was conducted in Viçosa $\left(20^{\circ} 45^{\prime} \mathrm{S}, 42^{\circ} 54^{\prime} \mathrm{W}, 650 \mathrm{~m}\right.$ altitude) Minas Gerais state, Brazil. Seeds were sown in $12 \mathrm{~L}$ pots, containing a mixture $30 \%$ sand and $70 \%$ soil. A half of plants was grown under black shade $40 \%$ of solar radiation treatment (T1), and the other half was exposed to full irradiation, constituting treatment T2. Despite the saturation irradiance was similar between treatments, the leaves at full sun exhibited higher photosynthesis, compensation irradiance and increased accumulation of dry mass. These results suggest a high acclimation of the photosynthetic machinery of $J$. curcas to the variation of irradiance.

Additional keywords: biofuel, renewable energy, environmental sustainability.

Fecha de recepción: 03-02-2009

Aprobado para publicación: 01-06-2009
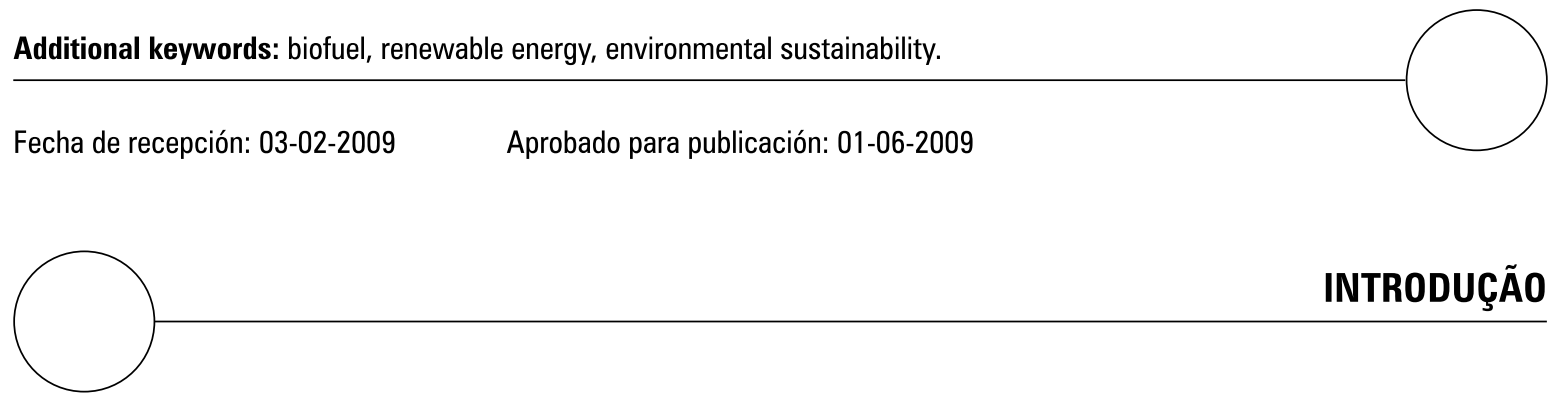

O incremento dos níveis dos gases de efeito estufa (GEE), notadamente dióxido de carbono $\left(\mathrm{CO}_{2}\right)$ na atmosfera terrestre, tem intensificado a busca por combustíveis renováveis, tipo biodiesel, visando reduzir o consumo de combustíveis fósseis. O combustível renovável denominado biodiesel consiste de metil ésteres de ácidos graxos, usualmente derivado de óleo vegetal ou animal. Diversas são as vantagens da utilização do biodiesel quando comparado com o diesel convencional, no entanto, a principal delas é a sustentabilidade da produção, isto porque a energia contida na cadeia de triacilglicerol é derivada da luz solar. Quando comparado com o diesel convencional, o biodiesel reduz a emissão de GEE em 40\% (Hill et al., 2006).

A cultura do pinhão manso (Jatropha curcas L.) é uma importante alternativa para produção de biodiesel. No atual contexto político, com o programa nacional de produção e uso do biodiesel (PNPB), esta cultura torna-se extremamente importante por produzir óleo com características semelhantes ao diesel. No entanto, os plantios têm sido estabelecidos com genótipos silvestres, com praticamente nenhum grau de melhoramento. O pinhão manso pertence à família das euforbiáceas, a mesma da mamona (Ricinus communis). É um arbusto, de crescimento rápido, cuja altura pode atingir de 2 a $3 \mathrm{~m}$, mas pode alcançar até $5 \mathrm{~m}$ em condições especiais. A planta adulta tem diâmetro do tronco de aproximadamente 20 $\mathrm{cm}$, com raízes curtas e pouco ramificadas, caule liso, de lenho mole e medula desenvolvida, mas pouco resistente a ventos e floema com longos canais que se estendem até as raízes, nos quais circulam o látex. $O$ tronco ou fuste é dividido desde a base, em compridos ramos, com numerosas cicatrizes provocadas pela queda das folhas na estação seca, as quais ressurgem logo após as primeiras chuvas (Arruda et al., 2004).

O óleo é extraído dos grãos de pinhão manso, os quais são submetidos a cozimento prévio e prensagem subseqüente em prensas tipo "expeller". Posteriormente, o óleo é filtrado, centrifugado e 
clarificado, resultando em um produto livre de impurezas (Ministério da Indústria e do Comércio, 1985). A torta resultante da prensagem dos grãos contém ainda, aproximadamente $8 \%$ de óleo, o qual é re-extraído com solventes orgânicos, geralmente hexano, sendo o farelo residual ensacado para aproveitamento como fertilizante natural, em virtude dos teores elevados de nitrogênio, fósforo, potássio e material orgânico. Desintoxicada, a torta pode também ser transformada em ração, como tem sido feita com a torta de Ricinus communis. O óleo do pinhão manso tem $83,9 \%$ do poder calorífico do óleo diesel, e a sua utilização pode gerar a mesma potência (Fundação CETEC, 1983).

Modificações nos níveis de luminosidade para os quais uma espécie está aclimatada pode acarretar diferentes respostas fisiológicas em sua características bioquímicas, anatômicas e de crescimento (Atroch et al., 2001). Em geral, as plantas desenvolvem "folhas de sol" e "de sombra", quando aclimatadas a diferentes níveis de luminosidade. Área foliar específica, espessura da cutícula, densidade estomática, cloroplastos com menos ou mais grana e menos ou mais tilacóides por granum, são algumas das características que variam em resposta à irradiância (Fahl et al., 1994). Obviamente, não apenas a irradiância interceptada, mas também a temperatura foliar deve variar ao longo do dossel, com possíveis reflexos sobre o comportamento estomático e a fotossíntese.

A atividade fotossintética é um parâmetro relacionado com o ganho de biomassa da planta. A análise de crescimento tem sido usada na tentativa de explicar diferenças no crescimento, de ordem genética ou resultante de modificações do ambiente (Peixoto, 1998) e constitui uma ferramenta muito eficiente para a identificação de materiais promissores (Benincasa, 2003), além de identificar características que, no crescimento inicial, indiquem possibilidade de aumento no rendimento da planta adulta, favorecendo os trabalhos de melhoramento na busca por materiais mais produtivos. $O$ fundamento da análi- se de crescimento baseia-se no fato de que, em média, $90 \%$ da matéria orgânica acumulada ao longo do crescimento da planta resultam da atividade fotossintética e o restante, da absorção mineral do solo (Benincasa, 2003). Em experimentos com culturas de ciclos longos, em que a mensuração da produtividade não seja possível devido ao longo período para desenvolvimento dos frutos, a mensuração da fotossíntese associada com a análise de crescimento da planta pode prever uma produtividade potencial da cultura. Não se conhece o grau de tolerância e a capacidade de aclimatação da maquinaria fotossintética do pinhão manso a fatores ambientais, como o sombreamento imposto pelo consórcio com outras culturas, que poderiam ser limitantes para a introdução desta espécie fora de seu habitat natural. Folhas submetidas ao sombreamento com irradiância inferior ao ponto de saturação luminoso possuem menor atividade fotossintética devido principalmente a menor energia fotoquímica disponível. $\mathrm{O}$ pinhão manso por ter evoluído em ambientes sob alta luminosidade, deve possuir relativamente baixa aclimatação de sua maquinaria fotossintética para ajustar-se à disponibilidade de luz. Tendo em vista a necessidade de buscar informações dessa natureza para a produção de mudas para o plantio em campo, bem como o melhor entendimento dos atributos para tolerar o sombreamento, possibilitando sua exploração comercial, avaliou-se neste trabalho o efeito do sombreamento sobre as características fisiológicas de folhas em mudas de J. curcas.

\section{MATERIAL E MÉTODOS}

\section{Material vegetal e condições de cultivo}

O experimento foi conduzido em Viçosa $\left(20^{\circ} 45^{\prime} \mathrm{S}\right.$, $42^{\circ} 54^{\prime} \mathrm{W}, 650 \mathrm{~m}$ de altitude, Minas Gerais, Brasil, em delineamento inteiramente casualizado. Sementes de J. curcas L. foram semeadas em vasos plásticos de $12 \mathrm{~L}$, contendo uma mistura de $30 \%$ de areia e 70\% de solo. Após a análise da composição química da mistura, foi realizada a adu- 
bação e a correção do pH, de acordo com análise de solo e recomendações técnicas para a cultura (Dias, 2000). A umidade do substrato foi mantida próxima à capacidade de campo, via irrigações periódicas. Metade das plantas foi cultivada sob telado (Sombrite ${ }^{\circledR}$ ) com $40 \%$ da radiação solar, constituíndo um tratamento $\left(T_{1}\right)$ e a outra metade a pleno sol constituindo outro tratamento $\left(T_{2}\right)$. As análises fisiológicas foram realizadas em folhas totalmente expandidas de plantas com 80 dias após a germinação.

\section{Trocas gasosas e parâmetros de fluorescência}

A taxa de assimilação líquida do carbono $(A)$, a condutância estomática $\left(g_{s}\right)$ e a razão entre as concentrações interna e ambiente de $\mathrm{CO}_{2}\left(C_{i} / C_{a}\right)$ foram medidas entre às 09:00-11:00 h, em sistema aberto, sob concentração de $\mathrm{CO}_{2}$ ambiente, com um analisador de gases a infravermelho portátil (LICOR 6400, Li-COR, Lincoln, NE). Curvas de resposta da taxa de assimilação liquida de carbono $(A)$ à irradiância (curva $A / R F A$ ) foram obtidas em laboratório, em folhas de ramos coletados no início da manhã, utilizando-se de um analisador de gases a infravermelho (LCprot, Analytical Development Company, Hoddesdon, UK), variando-se a RFA de 0 a $1.400 \mu \mathrm{mol}$ (fótons) $\mathrm{m}^{-}$ $2 \mathrm{~s}^{-1}$, a $25^{\circ} \mathrm{C}$, e concentração de $\mathrm{CO}_{2}$ constante de $380 \mu \mathrm{mol} \mathrm{mol}^{-1}$. Antes de se aplicar a RFA às folhas, foi fornecida uma concentração inicial de $\mathrm{CO}_{2}$ igual a $50 \mu \mathrm{mol} \mathrm{mol}{ }^{-1}$, por $3 \mathrm{~min}$, para induzir a abertura dos estômatos. $O$ rendimento quântico aparente $\left(\Phi_{\mathrm{a}}\right)$ foi estimado por meio da regressão linear da porção inicial da curva $[0 \leq$ $\mathrm{RFA} \leq 100 \mu \mathrm{mol}$ (fótons) $\left.\mathrm{m}^{-2} \mathrm{~s}^{-1}\right]$.

Os parâmetros de fluorescência da clorofila (CHL) a foram determinados naqueles horários, bem como na antemanhã, nas mesmas folhas utilizadas para as medições das trocas gasosas, por meio do fluorômetro com pulso modulado (FMS2, Hansatech, Norfolk, UK). Após serem adaptados ao escuro, por $30 \mathrm{~min}$, tecidos foliares foram inicialmente expostos a pulsos de luz vermelho-distante $\left[1-2 \mu \mathrm{mol}\right.$ (fótons) $\mathrm{m}^{-2} \mathrm{~s}^{-1}$ ] para a determinação da fluorescência inicial $\left(F_{0}\right)$. Em seguida, pulsos de luz saturante, com irradiância de $6.000 \mu \mathrm{mol}$ (fótons) $\mathrm{m}^{-2} \mathrm{~s}^{-1}$ e duração de $1 \mathrm{~s}$, foram aplicados para determinar a fluorescência máxima emitida $\left(F_{\mathrm{m}}\right)$. Nas amostras adaptadas ao escuro a eficiência máxima do FSII foi estimada pela razão entre as fluorescências variável e máxima, sendo a fluorescência variável obtida pela subtração entre a fluorescência máxima e mínima. $F / F_{m}=\left(F_{m}-F_{0}\right) / F_{m}$ Para a obtenção da fluorescência em steady-state $\left(F_{\mathrm{s}}\right)$, foi utilizada uma irradiância actínica artificial de 500 e 1000 $\mu \mathrm{mol}$ (fótons) $\mathrm{m}^{-2} \mathrm{~s}^{-1}$, respectivamente para plantas cultivadas à sombra ou a pleno sol. Essa irradiância, aplicada por $300 \mathrm{~s}$, foi equivalente à irradiância média interceptada pelas folhas à sombra e ao sol. Subseqüentemente, pulsos de luz saturante [6.000 $\mu \mathrm{mol}$ (fótons) $\mathrm{m}^{-2} \mathrm{~s}^{-1} ; 1 \mathrm{~s}$ ] foram aplicados para medir-se a fluorescência máxima das amostras sob luz $\left(F_{\mathrm{m}}{ }^{\prime}\right)$.

\section{Pigmentos fotossintéticos e nitrogênio}

Clorofilas e carotenóides totais (Car) foram quantificados espectrofotometricamente, utilizando quatro discos foliares $(1,4 \mathrm{~cm}$ de diâmetro). Amostras foliares foram coletadas e determinadas as diferenças de $\mathrm{N}$ orgânico e $\mathrm{N}$ nítrico, conforme descrito por Cataldo et al. (1974, 1975). A soma das duas frações representa o $\mathrm{N}$-total.

\section{Massa seca}

Após realizadas todas as análises não destrutivas, iniciou-se a separação da parte aérea e do sistema radicular, sendo ambos colocados em estufa à $80^{\circ} \mathrm{C}$ por $72 \mathrm{~h}$ para quantificação da massa seca da parte aérea e sistema radicular.

\section{Delineamento experimental e análise estatística}

$O$ experimento, em delineamento inteiramente casualizado, foi analisado considerando dois tratamentos, cinco repetições e parcelas de 1 muda por vaso. 
As análises de variância foram processadas e as diferenças entre médias dos tratamentos inferidas do próprio teste $\mathrm{F}$, em nível de $5 \%$ de probabilidade, das análises de variância.

\section{RESULTADOS}

\section{Trocas gasosas e parâmetros de fluorescência}

A irradiância de compensação $\left(I_{c}\right)$ foi, em média, $35,6 \%$ maior nas plantas a pleno sol, quando comparada com as plantas sombreadas, variando de 10,61 a $16,47 \mu \mathrm{mol}$ (fótons) $\mathrm{m}^{-2} \mathrm{~s}^{-1}$ (tabela 1 ). No entanto, a irradiância de saturação $\left(I_{s}\right)$ foi semelhante, independemente dos tratamentos (tabela 2), ficando em torno de $460 \mu \mathrm{mol}$ (fótons) $\mathrm{m}^{-2} \mathrm{~s}^{-1}$. A respiração foi, em média, 39,7\% maior nas folhas de $T_{2}$, quando comparada com folhas de $T_{1}$. A taxa de assimilação líquida do carbono saturada pela luz $\left(A_{\mathrm{RFA}}\right)$ foi semelhante, ao compararem-se as folhas de $T_{1}$ e $T_{2}$, enquanto o rendimento quântico aparente $\left(\Phi_{a}\right)$ foi, em média, 32,9\% maior em $\mathrm{T}_{2}$ quando comparada com a de $\mathrm{T}_{1}$. A taxa de assimilação líquida do carbono $(A)$, a condutância estomática $\left(g_{s}\right)$ e a razão entre a concentração interna e ambiente de $\mathrm{CO}_{2}\left(C_{\mathrm{i}} / C_{\mathrm{a}}\right)$ quando medidas em sistema aberto, sob luz e concentração de
$\mathrm{CO}_{2}$ ambientes, foram, em média, 48,0\%, 44,9\% e $63,6 \%$ maior nas folhas de $T_{2}$, quando comparada com folhas de $T_{1}$, respectivamente (Tabela 2). A razão $F_{v} / F_{\mathrm{m}}$ foi superior a $0,82 \mathrm{em}$ todos os tratamentos, indicando ausência de fotoinibição da fotossíntese (dados não mostrados).

\section{Nitrogênio total e pigmentos}

A concentração foliar de nitrogênio total, em base de massa, foi, em média, 20\% maior nas folhas de $T_{1}$ quando comparada com $T_{2}$. A área foliar unitária foi maior $(-59,2 \%)$ nas folhas de $T_{1}$ em relação às de $T_{2}$. A concentração de clorofilas totais, em base de massa, foi significativamente maior nas folhas de $T_{1}$ em relação às de $T_{2}$. A concentração de carotenóides totais (em base de massa) bem como a razão entre as clorofilas $a / b$ foi superior nas folhas de $T_{2}$ em relação à $T_{1}$, enquanto a razão entre clorofilas e carotenóides foi, em média, 60,8\% maior nas folhas de $T_{1}$ em relação às de $T_{2}$. As razões clorofilas totais/N e clorofilas/Car foram relativamente maiores nas folhas de $T_{1}$ em relação às de $T_{2}$, fatos explicáveis, principalmente, em função da maior concentração de clorofilas totais em $T_{1}$ A razão clorofila $a / b$ não respondeu estatisticamente aos diferentes tratamentos (tabela 2).

Tabela 1. Irradiância de compensação $\left[I_{\mathrm{c}^{\prime}} \mu \mathrm{mol}\right.$ (fótons) $\left.\mathrm{m}^{-2} \mathrm{~s}^{-1}\right]$, irradiância de saturação $\left[I_{\mathrm{s}^{\prime}} \mu \mathrm{mol}\right.$ (fótons) $\mathrm{m}^{-2}$ $\left.\mathrm{s}^{-1}\right]$, rendimento quântico aparente $\left[\Phi \mathrm{a}, \mathrm{mol}\left(\mathrm{CO}_{2}\right) \mathrm{mol}^{-1}\right.$ (fótons)], respiração $\left[\mathrm{R}_{\mathrm{d}} \mu \mathrm{mol} \mathrm{m}^{-2} \mathrm{~s}^{-1}\right]$ e taxa de assimilação líquida de carbono saturada pela luz $\left[A_{\mathrm{RFA}}, \mu \mathrm{mol}\left(\mathrm{CO}_{2}\right) \mathrm{m}^{-2} \mathrm{~s}^{-1}\right]$ obtidas a partir de curvas $A /$ RFA de folhas de Jatropha curcas $\mathrm{L}$.

\begin{tabular}{|c|c|c|}
\hline \multirow{2}{*}{ Parâmetros } & \multicolumn{2}{|c|}{ Tratamentos* } \\
\hline & T1 & $\mathrm{T} 2$ \\
\hline$I_{\mathrm{c}}$ & $10,61 \pm 1,71^{A}$ & $16,47 \pm 3,9 \mathrm{~A}$ \\
\hline$I_{s}$ & $458,5 \pm 1,07^{A}$ & $466,6 \pm 4,31^{A}$ \\
\hline$\Phi_{\mathrm{a}}$ & $0,049 \pm 0,004 \mathrm{~A}$ & $0,073 \pm 0,009 \mathrm{~A}$ \\
\hline$R_{d}$ & $0,44 \pm 0,020^{A}$ & $0,73 \pm 0,03^{A}$ \\
\hline$A_{\mathrm{RFA}}$ & $14,18 \pm 0,30^{A}$ & $13,35 \pm 0,75^{A}$ \\
\hline
\end{tabular}

*Valores representam a média \pm erro-padrão $(n=7)$. Médias seguidas pela mesma letra na linha não diferem entre si, a $5 \%$ de probabilidade, pelo teste $\mathrm{F}$. $\mathrm{T}_{1}$ : plantas à sombra $\left(40 \%\right.$ de radiação solar); $\mathrm{T}_{2}$ : plantas a pleno sol. 


\begin{tabular}{|c|c|c|}
\hline \multirow{2}{*}{ Parâmetros } & \multicolumn{2}{|c|}{ Tratamentos } \\
\hline & $\mathrm{T}_{1}$ & $\mathrm{~T}_{2}$ \\
\hline$A, \mu \mathrm{mol}\left(\mathrm{CO}_{2}\right) \mathrm{m}^{-2} \mathrm{~s}^{-1}$ & $4,96 \pm 0,26^{\mathrm{B}}$ & $9,54 \pm 0,90^{A}$ \\
\hline$g_{s^{\prime}} \mathrm{mmol}\left(\mathrm{H}_{2} \mathrm{O}\right) \mathrm{m}^{-2} \mathrm{~s}^{-1}$ & $0,138 \pm 0,008^{A}$ & $0,076 \pm 0,011^{B}$ \\
\hline $\mathrm{C}_{i} / \mathrm{C}_{a}$ & $0,77 \pm 0,09^{A}$ & $0,28 \pm 0,06^{B}$ \\
\hline $\mathrm{N}$ total, $\mathrm{g} \mathrm{kg}^{-1} \mathrm{MS}$ & $24,81 \pm 0,41^{A}$ & $19,84 \pm 0,38^{\mathrm{B}}$ \\
\hline $\mathrm{Cl}(\mathrm{a}+\mathrm{b}), \mathrm{g} \mathrm{kg}^{-1} \mathrm{MS}$ & $6,12 \pm 0,32^{A}$ & $3,18 \pm 0,18^{B}$ \\
\hline Car, $\mathrm{g} \mathrm{kg}^{-1} \mathrm{MS}$ & $0,94 \pm 0,12^{A}$ & $1,19 \pm 0,13^{\mathrm{A}}$ \\
\hline $\mathrm{Cl} / \mathrm{N}, \mathrm{mmol} \mathrm{mol}^{-1}$ & $6,40 \pm 0,20^{A}$ & $2,69 \pm 0,18^{B}$ \\
\hline $\mathrm{Cl} \mathrm{a/b}$ & $1,77 \pm 0,25^{A}$ & $2,44 \pm 0,43^{A}$ \\
\hline $\mathrm{Cl} / \mathrm{Car}$ & $7,27 \pm 1,36^{A}$ & $2,85 \pm 0,35^{\mathrm{B}}$ \\
\hline
\end{tabular}

Valores representam a média \pm erro-padrão $(n=7)$. Médias seguidas pela mesma letra na linha não diferem entre si, a $5 \%$ de probabilidade, pelo teste $\mathrm{F}$. $\mathrm{T}_{1}$, plantas à sombra $\left(40 \%\right.$ de radiação solar); $\mathrm{T}_{2}$, plantas a pleno sol.

\section{Análise de crescimento}

A massa seca da parte aérea e sistema radicular foram, em média, 33,6\% e 64,0\% maiores nas folhas de $\mathrm{T}_{2}$ em relação às de $\mathrm{T}_{1}$, respectivamente, resultando em uma razão parte aérea/sistema radicular $46,5 \%$ maior no tratamento $T_{2}$, quando comparado com $T_{1}$. No entanto, o diâmetro do caule e altura das plantas, foram maiores no tratamento $\mathrm{T}_{1}$ (tabela 3)

\section{DISCUSSÃo}

\section{Aclimatação a baixas irradiâncias}

Este trabalho é o primeiro a explorar as características fisiológicas de mudas de Jatropha curcas L. De modo geral, a área foliar unitária aumentou nas folhas mais sombreadas. O incremento da superfície foliar pode ser atribuído tanto ao aumento do número de células, devido ao aumento

Tabela 3. Área foliar, massa seca da parte aérea e sistema radicular, diâmetro do caule e altura da planta de Jatropha curcas $\mathrm{L}$. distribuídas em dois tratamentos, correspondendo aos tratamentos à sombra $\left(T_{1}\right)$ e a pleno sol $\left(T_{2}\right)$.

\begin{tabular}{|c|c|c|}
\hline \multirow{2}{*}{ Parâmetros } & \multicolumn{2}{|c|}{ Tratamentos } \\
\hline & $\mathrm{T} 1$ & $\mathrm{~T} 2$ \\
\hline Área foliar (cm) & $397 \pm 22,0^{A}$ & $162 \pm 12,3^{B}$ \\
\hline Massa seca parte aérea (g) & $4,24 \pm 0,29^{B}$ & $6,29 \pm 0,63^{A}$ \\
\hline Massa seca raiz (g) & $0,63 \pm 0,038^{B}$ & $1,78 \pm 0,23^{A}$ \\
\hline Razão parte aérea/ raiz & $6,77 \pm 0,23^{A}$ & $3,62 \pm 0,28^{\mathrm{B}}$ \\
\hline Diâmetro do caule $(\mathrm{cm})$ & $1,58 \pm 0,058^{A}$ & $1,12 \pm 0,020^{B}$ \\
\hline Altura da planta $(\mathrm{cm})$ & $14,78 \pm 1,14^{A}$ & $13,52 \pm 0,83^{A}$ \\
\hline
\end{tabular}

Valores representam a média \pm erro-padrão $(n=7)$. Médias seguidas pela mesma letra na linha não diferem entre si, a $5 \%$ de probabilidade, pelo teste $\mathrm{F}$. $T_{1}$, plantas à sombra (40\% de radiação solar); $T_{2}$, plantas a pleno sol. 
das divisões celulares, quanto ao maior volume celular (Fahn, 1990). Nesse sentido, nas folhas das plantas cultivadas à sombra, a expansão celular pode ter sobrepujado as divisões celulares que acarretam aumento do número de células. Apesar do fato de o número de divisões celulares ser controlado geneticamente (Nadeau e Sack, 2003), o ambiente pode exercer forte pressão e alterar esse padrão. Dessa forma, folhas sombreadas, freqüentemente, apresentam incremento do número de divisões celulares, como forma de aumentar a área foliar, conforme descrito para Populus sp. (Ceulemans et al., 1995).

Fisiologicamente, a baixa $I_{c}$ deve permitir a obtenção de um balanço positivo de carbono sob irradiâncias extremamente baixas. Os valores reduzidos de $I_{c}$ observados nas folhas mais sombreadas permitiu a obtenção de um balanço positivo de carbono sob menor irradiância. Isso esteve provavelmente associado com uma menor taxa respiratória, maior concentração de clorofilas totais em base de massa e maior razão $\mathrm{Cl} / \mathrm{N}$. A maior razão $\mathrm{Cl} / \mathrm{N}$ nas folhas de sombra indica maior alocação de $\mathrm{N}$ para produção de pigmentos fotossintéticos, em detrimento de compostos diretamente envolvidos na fixação do $\mathrm{CO}_{2}$ (Evans, 1989; Ellsworth e Reich, 1993). No entanto, não ocorreu redução da razão $\mathrm{Cl} / a / b$ - uma das principais respostas observadas em plantas (folhas) desenvolvidas à sombra (Walters, 2005). Contudo, a razão $\mathrm{Cl} / a / b$ não foi afetada pelas variações da irradiância. Essa razão é um indicador da proporção de complexos coletores de luz associados ao FSII (CCL-II), em relação a outros complexos contendo clorofilas (Murchie \& Horton, 1997). As menores concentrações de carotenóides, bem como, menor razão clorofila/carotenóide nas folhas de $T_{1}$ resultam em menor fotoproteção nas folhas deste tratamento. Isso poderia explicar, em parte, o porque de mudas de pinhão manso, quando transferidas de viveiros sombreados para o campo exibirem, usualmente, sintomas típicos de escaldadura (danos fotooxidativos).

A menor massa seca das plantas de $T_{1}$ está possivelmente associada a menor atividade fotossinté- tica nas plantas deste tratamento, uma vez que a atividade fotossintética mensurada em sistema aberto nestas folhas foi muito inferior a atividade fotossintética de $T_{2}$.

Os resultados sugerem que o pinhão manso possui relativamente alta aclimatação da maquinaria fotossintética à disponibilidade de luz, particularmente a $I_{c}$, que deve estar intimamente relacionada com a aclimatação de $J$. curcas a baixas irradiâncias, e em boa extensão, pode explicar um possível sucesso do cultivo da espécie em condição de consórcio com outras culturas.

\section{Aclimatação a altas irradiâncias}

A maior massa seca nas plantas de $T_{2}$ esteve associado a maior atividade fotossintética nas folhas deste tratamento, enquanto o menor diâmetro do caule das plantas de $T_{2}$ pode ser resultado da menor alocação de assimilados para o caule. A menor razão $\mathrm{C}_{\mathrm{i}} / \mathrm{C}_{\mathrm{a}}$ nas folhas à pleno sol, está intimamente relacionada a maior taxa de assimilação líquida do carbono (A) nestas folhas, uma vez que não houve restrição estomática. No entanto, a maior disponibilidade de energia luminosa parece explicar a maior atividade fotossintética das folhas de $T_{2}$. As plantas podem apresentar diversos meios para se protegerem contra irradiâncias potencialmente fotoinibitórias. Neste trabalho, a redução da concentração de clorofilas, nas folhas de $T_{2}$ em relação às folhas de $T_{1}$, deve ter auxiliado na redução da absortância foliar e, associada com os menores valores da eficiência de captura de energia de excitação pelos centros de reação abertos do PSII, reduzido a quantidade total de energia efetivamente absorvida pelos fotossistemas. Decréscimos na concentração de clorofilas totais em folhas submetidas a maiores níveis de irradiância podem estar associados a processos fotoxidativos (e.g., Krause, 1988), ou estar relacionado com alterações na organização dos fotossistemas, de modo a servir como um mecanismo fotoprotetor (e.g., Elvira et al., 1998; Ottander et al., 1995). A segunda hipótese é mais provável, uma vez que não houve qualquer indício de dano oxidativo (razão $F_{\mathrm{v}} / F_{\mathrm{m}} \geq 0,82$ ), ape- 
sar da grande diferença da irradiância interceptada entre as folhas dos tratamentos. Conforme esperado, houve um decréscimo na razão $\mathrm{Cl} / \mathrm{Car}$ nas folhas sob maiores níveis de luz, de modo a permitir-lhes um aumento na capacidade de dissipação da energia de excitação, principalmente via ciclo das xantofilas (Demmig-Adams e Adams, 1996a; Ma et al., 2003). Com efeito, a elevação na concentração de carotenóides e/ou uma redução da concentração de clorofilas pode auxiliar as plantas a minimizarem a fotooxidação (Corcuera et al., 2005).

Desta forma, as mudas desenvolvidas a pleno sol, apresentam características fisiologicamente desejáveis como maiores taxas fotossintética, ca- pacidade de dissipação do excesso de energia luminosa e maior rendimento quântico, bem como maior acúmulo de massa seca, o que corrobora com a origem da espécie em ambiente de elevada irradiância, supostamente regiões semi-áridas.

\section{CONCLUSÕES}

Tomados em conjunto, estes resultados explicam, em boa extensão, um possível sucesso do cultivo da espécie à sombra ou a pleno sol, ainda que tenha evoluído em ambientes a pleno sol. As mudas de J. curcas $\mathrm{L}$. demonstraram relativa variação das características fisiológicas quando submetidas a diferentes irradiâncias.

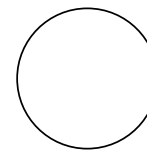

Arruda, F.P. de; N.E. de M. Beltrão; A.P. de Andrade; W.E. Pereira e L.S. Severino. 2004. Cultivo do Pinhão manso (Jatropha curcas L.) como alternativa para o semi-árido nordestino. Revista Brasileira de Oleaginosas e Fibrosas 8(1), 789-799.

Atroch, E.M.A.C.; A.M. Soares; A.A. Alvarenga e E.M. Castro. 2001. Crescimento, teor de clorofilas, distribuição de biomassa e características anatômicas de plantas jovens de Bauhinia forticata Link submetidas a diferentes condições de sombreamento. Ciência e Agrotecnologia 25, 853-862.

Benincasa, M.M.P. 2003. Análise de crescimento de plantas: noções básicas. Funep, Jaboticabal, Brasil.

Cataldo, D.A.; L.E. Schrader e V.L. Youngs. 1974. Analysis by digestion and colorimetric assay of total nitrogen in plant tissues high in nitrate. Crop Sci. 14, 854-856.

Cataldo, D.A.; M. Haroon; L.E. Schrader e V.I. Youngs. 1975. Rapid colorimetric determination of nitrate in plant tissue by nitration of salicylic acid. Comm. Soil Sci. Plant Anal. 6, 71-80.

Ceulemans, R.; L.V. Praet e X.N. Jiang. 1999. Effects of $\mathrm{CO}_{2}$ enrichment, leaf position and clone on stomatal index and epidermal cell density in poplar (Populus). New Phytologist 131, 99-107.

\section{REFERÊNCIAS BIBLIOGRAFICAS}

Corcuera, L.; F. Morales; A. Abadía e E. Gil-Pelegrín. 2005 Seasonal changes in photosynthesis and photoprotection in a Quercus ilex subsp. ballota woodland located in its upper altitudinal extreme in the Iberian Peninsula. Tree Physiol. 25, 599-608.

Demmig-Adams, B. e W.W. Adams. 1996. Photoprotection and other responses of plants to high light stress. Annu. Rev. Plant Physiol. Plant Mol. Biol. 43, 599-626.

Dias, L.A.S. 2000. Calagem e adubação. pp. 18-20. In: Cultivo de pinhão manso Jatropha curcas L. para produção de óleo combustível. Universidade Federal de Viçosa, Viçosa, Brasil.

Ellsworth, D.S. y P.B. Reich. 1993. Canopy structure and vertical patterns of photosynthesis and related leaf traits in a deciduous forest. Oecologia 96, 169-178.

Elvira, R.; S. Alonso; J. Castilho e B.S. Gimeno. 1998. On the response of pigments and antioxidants of Pinus hapelensis to mediterranean climate factors and long-term ozone exposure. New Phytologist 138, 419-432.

Evans, J.R. 1989. Photosynthesis and nitrogen relationship in leaves of $\mathrm{C}_{3}$ plants. Oecologia 78, 9-19.

Fahl, J.I.; M.L.C. Carelli; J. Vega e A.C. Magalhães. 1994. Nitrogen and irradiance levels affecting net pho- 
tosynthesis and growth of young coffee plants (Coffea arabica L.). J. Hort. Sci. 69, 161-169.

Fahn, A. 1990. Plant anatomy. $2^{\text {nd }}$ ed. Butterworth Heinemann, Oxford, UK.

Fundação Centro Tecnológico de Minas Gerais (CETEC). 1983. Produção de biocombustíveis líquidos a partir de óleos vegetais. Relatório final. Belo Horizonte, Brasil.

Hill, J.; E. Nelson; D. Tilman; S. Polasky e D. Tiffany. 2006. Environmental, conomic, and energetic costs and benefits of biodiesel and ethanol biofuels. Proc. Natl. Acad. Sci. USA 103, 11206-11210.

Krause, G.H. 1988. Photoinhibition of photosynthesis - an evaluation of damaging and protective mechanisms. Physiol. Plant. 74, 566-574.

Ma, Y-Z.; N.E. Holt; X.-P. Li; K.K. Niyogi e G.R. Fleming. 2003. Evidence for direct carotenoid involvement in the regulation of photosynthetic light harvesting. Proc. Natl. Acad. Sci. USA 100, $4377-$ 4382 .
Ministério da indústria e do comércio. Secretária de tecnologia industrial. 1985. Produção de combustíveis líquidos a partir de óleos vegetais. STI/CIT, Brasília.

Murchie, E.H. e P. Horton. 1997. Acclimation of photosynthesis to irradiance and spectral quality in British plant species: Chlorophyll content, photosynthetic capacity and habitat preference. Plant Cell Environ. 20, 438-448.

Nadeau, J.A. e F.D. Sack. 2003. Control of stomata distribution on the Arabidopsis leaf surface. Sci. 296, 1700.

Ottander, C.; D. Campbell e G. Oquist. 1995. Seasonal changes in photosystem-Ii organization and pigment composition in Pinus-Sylvestris. Planta 197, 176-183.

Peixoto, C.P. 1998. Análise de crescimento e rendimento de três cultivares de soja em três épocas de semeadura e três densidades de plantas. Tese (Doutorado em Fitotecnia). Escola Superior de Agricultura Luiz de Queiroz, Universidade de São Paulo, Piracicaba, Brasil

Walters, R.G. 2005. Towards an understanding of photosynthetic acclimation. J. Exp. Bot. 56, 435-447. 